\title{
BMJ Open Mechanical prophylaxis after hip fracture: what is the risk of deep vein thrombosis? A retrospective observational study
}

\author{
Majd B Protty, Shridhar Aithal, Ben Hickey, Rebecca Pettit, Antony Johansen
}

To cite: Protty MB, Aithal S, Hickey B, et al. Mechanical prophylaxis after hip fracture: what is the risk of deep vein thrombosis? A retrospective observational study. BMJ Open 2015;5:e006956. doi:10.1136/bmjopen-2014006956

- Prepublication history and additional material for this paper is available online. To view these files please visit the journal online (http://dx.doi.org/10.1136/ bmjopen-2014-006956).

Received 21 October 2014 Revised 26 December 2014 Accepted 5 January 2015

CrossMark

Trauma Unit, University Hospital of Wales, Cardiff, UK

Correspondence to Dr Majd B Protty; majd@protty.net

\section{ABSTRACT}

Graduated compression stockings carry a potential risk of pressure, vascular and other complications. Current understanding of deep vein thrombosis (DVT) risk leaves it uncertain whether patients with hip fracture should wear stockings on both legs.

Objectives: To determine the association between the side of the hip fracture and the subsequent occurrence of symptomatic lower limb DVT.

Setting: Single tertiary trauma centre, Wales.

Participants: All 3657 patients presenting with hip fracture between 2007 and 2013 were identified from our unit's National Hip Fracture Database. We excluded 404 patients $(11.0 \%)$ resident outside our catchment area, leaving a total of 3253 . Median age was 83 years $( \pm 12.4)$.

Primary/secondary outcome measures: We crosslinked patient details with Medical Physics records, to identify $634(19.5 \%)$ who had undergone one or more lower-limb Doppler-ultrasound scans at some point during the study period. The distribution rates of DVT were calculated from this resulting data set.

Results: Many of the total 634 scans were unrelated to the hip fracture, including $225(35.5 \%)$ performed prior to the fracture. We calculated a baseline rate of DVT of $3.7 / 1000$ patients per year, for the 3-month period immediately before the hip fracture. Scans performed following hip fracture showed DVT risk to be highest in the 3-month period after fracture (35.7/1000 patients per year). This resulted from a six-fold increase in DVTs on the side of the fracture $(29.5 / 1000$ patients per year, $p<0.01)$. We found only a very small non-significant increase in DVT on the contralateral leg (6.1/1000 patients per year)

Conclusions: The additional risk of DVT after hip fracture is essentially confined to the fractured limb-the leg to which it is most painful to apply stockings. There appears little justification for the cost and potential risk of using stockings on the contralateral leg.

\section{INTRODUCTION}

Virchow's triad ${ }^{1-3}$ proposes deep vein thrombosis (DVT) to occur as a result of alterations in blood flow, vascular endothelial damage and alterations in the constituents of the blood.

\section{Strengths and limitations of this study}

- The study is the first of its kind to examine the tendency of deep vein thrombosis to lateralise to the hip fracture side.

- This has not been described in the literature before and has significant therapeutic implications especially in terms of targeting mechanical thromboprophylaxis to the high-risk limb.

- Further study is necessary to determine the costeffectiveness of application of below knee antiembolic stocking to the lower limb contralateral to the hip fracture and determine the relative risk-benefit ratio.

A combination of older age, lower limb trauma, hospitalisation, immobility and orthopaedic surgery puts hip fracture patients at high risk $(\mathrm{OR}>10)$ of venous thromboembolism (VTE), with symptomatic pulmonary embolism (PE) affecting 6\% of patients following hip fracture surgery in the absence of thromboprophylaxis. ${ }^{4-8}$ VTE is a life changing event even in patients who survive acute PE, postphlebitic syndrome can cause chronic leg ulceration, and recurrent thromboembolism carries a risk of pulmonary hypertension and death. ${ }^{9}$

Chemical prophylaxis significantly reduces the incidence of DVT. ${ }^{8}$ Anticoagulants can target the hypercoagulability element of Virchow's triad, but do not influence venous stasis.

Evidence that this element of increased risk can be reduced by mechanical prophylaxis remains poor, ${ }^{10}{ }^{11}$ but the National Institute for Health and Care Excellence (NICE) advocates the use of mechanical measures to reduce venous stasis as part of a dual approach. ${ }^{12}$

This recommendation is broadly followed by units across the UK, but compression stockings are difficult to apply to a fractured limb. Staff working in trauma wards will be 
familiar with the sight of a frail or confused elderly patient wearing a stocking on their 'good leg', but not on the painful limb in which they have a hip fracture.

Experience in patients with stroke exemplifies a further concern. National guidelines now recommend against using compression stockings after stroke, ${ }^{12} 13$ earlier presumptions as to their benefit having been revised when the CLOTS2 trial defined the extent of vascular and pressure complications that result from their use. $^{14}$

Similar concerns may prove relevant to the equally frail, older patients who typically present with hip fracture. Many will have local vascular or skin contraindications to the use of stockings. Even when not contraindicated, compliance and persistence with wearing stockings is poor, not least because over half of the patients have dementia or delirium. ${ }^{11}$ Such considerations mean that it is unlikely that a trial equivalent to CLOTS2 will ever be possible within this population.

Risk of clinical DVT is poorly described in the current era where expedited hip fracture surgery, early postoperative mobilisation and the use of chemicals are increasingly routine.

None of the published evidence has considered the relative benefits of applying stockings to the affected limb and unaffected leg following hip fracture, despite the potential risks of this intervention, the costs of stockings and nursing time.

Vessel wall injury is more prevalent in the vicinity of the fractured, operated hip, so our primary aim was to determine the association between the side of the hip fracture and the subsequent occurrence of symptomatic lower limb DVT.

\section{METHODS}

This study considers the risk of clinical DVT in a population that routinely received chemical but not mechanical prophylaxis.

Our departmental approach to chemical thromboprophylaxis after hip fracture changed following publication of the NICE guideline in $2010 .{ }^{12}$ Before this date our policy was to consider aspirin in all patients, ${ }^{15}$ but this changed to routine consideration of enoxaparin from June 2010. A number of local audits have confirmed the reliable provision of aspirin or enoxaparin to all patients in whom these were not contraindicated, but concern over potential for pressure and ischaemic complications $^{14}$ meant that rates of mechanical prophylaxis remained below $10 \%$ across the whole study period.

As part of our departmental clinical governance programme we used locally held National Hip Fracture Database (NHFD) data at our teaching hospital to identify all patients admitted with hip fracture between March 2007 and December 2013. The NHFD data set included patient case-mix, admission dates and the side of hip fracture. Ethical approval was obtained as part of this local clinical governance process.
All patients who had undergone lower limb Doppler ultrasound scans during the same study period were identified in a search using their hospital identifiers to extract records from our Department of Medical Physics. These records included the dates and results of the Doppler scans.

These two databases were cross-referenced and data linked using the patient's hospital identifier as the primary key. A proportion of patients who presented with hip fracture were normally resident outside our catchment area. Since these people might present with DVT either to our hospital or to other hospitals, we excluded them from further analysis.

\section{RESULTS}

The combined NHFD and Doppler data set included 3657 patients. Four hundred and four $(11 \%)$ of these were resident outside our catchment area, and were excluded from further analysis.

The remaining $3253(89 \%)$ patients' had a median age of 83 and $2349(72.2 \%)$ were women (table 1). Hip fracture was non-significantly more common on the left $(53.5 \%)$.

A total of 634 lower limb Doppler ultrasound scans were performed. This equates with approximately one scan for every five patients $(19.5 \%)$ during this 7-year time period.

Many of these scans were unrelated to the index hip fracture, including $225(35.5 \%)$ which were performed prior to the admission with hip fracture. A total of 278 $(43.8 \%)$ were performed within the 6-month period immediately following admission with hip fracture.

In the 6 months immediately following admission, positive scans showed a significant tendency for DVTs to occur on the same side as the hip fracture, $\mathrm{p}<0.001$ (table 2).

We considered the rate of DVT for 3-month intervals before and after admission. The standardised rate of

\begin{tabular}{lc} 
Table 1 Demographics of patients included in the study \\
\hline Age (median \pm SD) & $83 \pm 12.44$ \\
Sex (\% female) & $2349(72.2 \%)$ \\
Side of hip \# (\% left) & $1741(53.5 \%)$ \\
Type of hip fracture & \\
$\quad$ Intertrochanteric & $1129(34.7 \%)$ \\
$\quad$ Intracapsular-displaced & $1503(46.2 \%)$ \\
$\quad$ Intracapsular-undisplaced & $316(9.7 \%)$ \\
$\quad$ Subtrochanteric & $173(5.3 \%)$ \\
Other & $124(3.8 \%)$ \\
Type of operation & \\
Hemiarthroplasty & $1243(38.2 \%)$ \\
Total hip replacement & $196(6.0 \%)$ \\
$\quad$ Internal fixation (IM Nail) & $365(11.2 \%)$ \\
$\quad$ Internal fixation (Screws) & $270(8.3 \%)$ \\
Internal fixation (SHS) & $1032(31.7 \%)$ \\
$\quad$ Non-operative & $120(3.7 \%)$ \\
Total number of patient-episodes & 3253 \\
\hline IM, intramedullary; SHS, sliding hip screw.
\end{tabular}




\begin{tabular}{|c|c|c|}
\hline Doppler scans (\%) & 634 (19.5\%) & \\
\hline $\begin{array}{l}\text { Relevant scans ( } \leq 180 \text { days from } \\
\text { admission) }\end{array}$ & $278(43.8 \%)$ & \\
\hline No DVT & 237 (85.3\%) & \\
\hline Ipsilateral DVT & $31(75.6 \%)$ & $p<0.001$ \\
\hline Contralateral DVT & $10(24.4 \%)$ & \\
\hline Pre-admission scans & 225 (35.5\%) & \\
\hline No DVT & 200 (88.9\%) & \\
\hline Right-sided DVT & $16(64.0 \%)$ & $\mathrm{p}=0.162$ \\
\hline Left-sided DVT & $9(36.0 \%)$ & \\
\hline
\end{tabular}

DVT was highest (35.7/1000 patient-episodes per year) in the 3 months immediately after the fracture. This was significantly higher than in the preceding or succeeding quarters, and showed a marked tendency $(82.8 \%$, $\mathrm{p}<0.001)$ to occur in the same limb as the hip fracture (figure 1).

We examined the rate of DVT in the 6 months immediately after hip fracture (table 3 ), and found a nonsignificant fall in the rates after our departmental policy change from the use of aspirin to enoxaparin in June 2010 (16.2 vs 9.4/1000 patients per year, $\mathrm{p}=0.082$ ) There was no statistically significant difference in patient demographics for those who sustained hip fracture before and after June 2010.

Finally, we observed that the increased risk of DVT was confined to the 6 months after hip fracture. Beyond this time point the rate of DVTs fell below pre-fracture levels (figure 1). The very limited number of referrals for Doppler scans meant that this fall was not significantly different from the baseline pre-fracture rate, but perhaps indicates that clinicians are reassured when a patient has reached this time after injury, or are reluctant to refer frail and immobile patients once they have left hospital.

\section{DISCUSSION}

In the hands of an experienced operator, Doppler has been reported to have a sensitivity of $100 \%$, specificity of

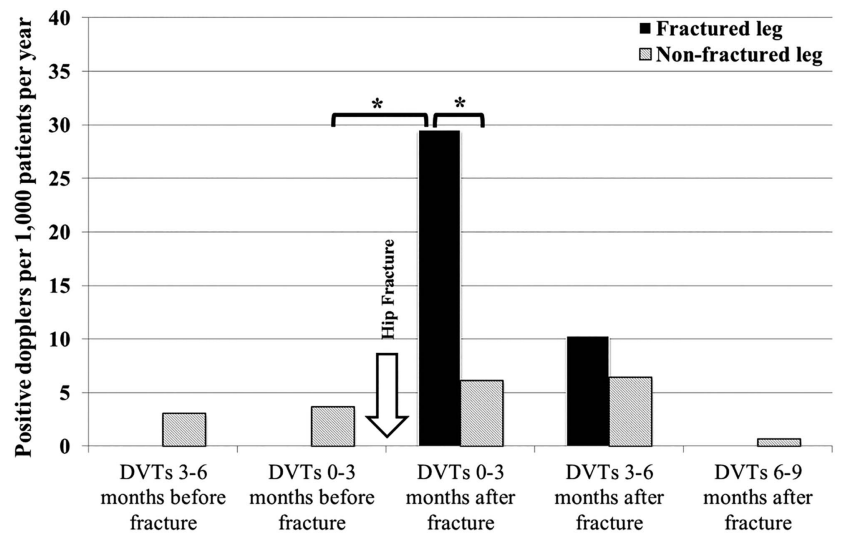

Figure 1 The three monthly rate of deep vein thromboses (DVTs) before and after hip fractures $\left({ }^{*} p<0.05\right)$.
Table 3 The effect of change of practice (June 2010) on DVT rates

\begin{tabular}{lrll}
\hline Relevant Doppler scans & 278 & $43.8 \%$ & \\
$\leq 180$ days from admission (\%) & & & \\
Doppler scans performed & 150 & $54.0 \%$ & \\
pre-2010 & & & \\
$\quad$ No DVT & 125 & $83.3 \%$ & \\
DVT & 25 & $16.7 \%$ & \\
$\quad$ Ipsilateral DVT & 19 & $76.0 \%$ & $\mathrm{p}<0.009$ \\
$\quad$ Contralateral DVT & 6 & $24.0 \%$ & \\
Doppler scans performed & 128 & $46.0 \%$ & \\
post-2010 & & & \\
$\quad$ No DVT & 112 & $87.5 \%$ & \\
DVT & 16 & $12.5 \%$ & \\
$\quad$ Ipsilateral DVT & 12 & $75.0 \%$ & $\mathrm{p}<0.046$ \\
$\quad$ Contralateral DVT & 4 & $25.0 \%$ & \\
Difference between pre-2010 and & & & $\mathrm{p}=0.082$ \\
post-2010 DVTs & & & \\
\hline DVT, deep vein thrombosis. & & & \\
\end{tabular}

98\% and accuracy of $98 \%$ for lower limb DVT when compared with venography. ${ }^{16}$ In our hospital, Doppler is standard practice and has replaced venography. None of our patients was found to have a DVT when repeat scans were performed after an initial negative Doppler result.

We have shown that a significant increase in risk of symptomatic, Doppler proven DVT only occurs in the limb affected by the hip fracture. This suggests that local vessel compression and injury are more important than immobility and general hypercoagulability in causing DVT after hip fracture.

This observation has not previously been described in this patient group. A study of venous stasis in 126 hip fracture patients used strain gauge plethysmography before and 6 weeks after surgery. Venous outflow and venous capacitance were significantly reduced in both legs postoperatively compared with preoperatively, with a significantly greater reduction in the ipsilateral limb. ${ }^{17}$ This suggested that this element of DVT risk persists for several weeks after surgery for hip fracture. The role of extended chemical thromboprophylaxis in patients with hip fracture was supported by the recent SAVE-HIP3 study, which found a $79 \%$ relative risk reduction in VTE or all cause death $(18.6 \%$ vs $3.9 \%, \mathrm{p}<0.001)$ if patients were provided with extended duration chemical thromboprophylaxis. ${ }^{18}$

No other published studies have considered the laterality of symptomatic DVT in relation to hip fracture. However, in a study of 76 patients with acute onset stroke causing hemiplegia or paresis, DVT occurred in $53 \%$ of the paralysed legs and $7 \%$ of the non-paralysed legs, this difference was highly statistically significant. ${ }^{19}$ Patients with hip fracture or stroke tend to be demographically comparable, and although hip fracture does not cause hemiplegia, it will result in pain and reduce movement in the lower limb.

Our findings may not be surprising, but they have significant clinical implications. 
There is very limited evidence to support mechanical thromboprophylaxis in the form of antiembolic stockings. Randomised controlled trials (RCTs) show that compression stockings can reduce the occurrence of DVT in hospitalised patients, but evidence for this in patients with hip fracture is limited..$^{20}$ None of the studies included in this Cochrane review of 18 RCTs considered patients with hip fractures. Only five of the included studies were of orthopaedic patients-undergoing elective hip or knee arthroplasty. ${ }^{21-25}$ Such patients tend to be younger and fitter than those who undergo hip fracture surgery, and it may be incorrect to generalise these findings to patients with hip fracture. ${ }^{26}$

Another option for mechanical thromboprophylaxis in patients with hip fracture is calf or foot compression. These approaches may be effective in reducing the incidence of DVT, ${ }^{27}$ but the size and weight of the pumps make them difficult to use, and they can prove to be a limitation to mobility, a falls risk and a source of confusion among frailer patients.

In our study, fewer than one-fifth of symptomatic DVTs occurred in the contralateral, un-fractured lower limb $(6.1 / 1000$ patients with hip fracture per year, figure 1). This was not significantly higher than the background rate of DVT per lower limb (3.7/1000 per year) seen in the same patients before hip fracture. Even if a much larger study confirmed this difference to be statistically significant, then the most generous possible assumptions (that all patients are $100 \%$ compliant and that stockings halve the risk of $\mathrm{DVT}^{20}$ ) would imply that 800 patients would need to wear a stocking on their contralateral leg to prevent one clinical DVT. This numbers needed to treat (NNT) figure of 800 stands in dramatic contrast to the numbers needed to harm $(\mathrm{NNH})$ of 20 for skin complications described in the CLOTS2 study after stroke. ${ }^{14}$

Despite the high sensitivities and specificities that have been described in the literature for the expert use of lower limb Doppler studies to detect DVT, ${ }^{16}$ in real-life terms, it is difficult to guarantee that all operators can achieve this level of accuracy consistently. In addition, it is not possible to use this technique to detect pelvic deep vein thrombi, which in any case would not be affected by any mechanical thromboprophylaxis measures.

It is important to set any possible benefit of using antiembolic stockings in the unfractured lower limb against risks such as pressure ulceration. In addition, stockings carry a significant cost, particularly in respect of the nursing time associated with excluding contraindications before their application, and with ensuring they are properly applied and remain correctly positioned without complications. ${ }^{29}{ }^{30}$ Further study is necessary to determine the risk-benefit ratio and cost-effectiveness of compression stockings for the contralateral leg following hip fracture.

\section{CONCLUSION}

We have shown that symptomatic lower limb DVT is significantly more likely to occur in the lower limb ipsilateral to the hip fracture. We suggest mechanical thromboprophylaxis strategies be developed to target this. Our finding that enoxaparin had no benefit over aspirin on the outcome of symptomatic DVT requires further evaluation in prospective studies in patients with hip fracture.

Contributors MBP, BH and AJ conceived the idea for the study. MBP, SA, RP and $\mathrm{AJ}$ acquired and provided the data. MBP and AJ managed the data and conducted the analysis. BH, SA and RP contributed to the analysis review. The initial manuscript draft was written by MBP, SA, BH and AJ. All authors contributed to the revision of the manuscript for intellectual content and approved the final version.

Funding This research received no specific grant from any funding agency in the public, commercial or not-for-profit sectors.

\section{Competing interests None.}

Provenance and peer review Not commissioned; externally peer reviewed.

Data sharing statement No additional data available.

Open Access This is an Open Access article distributed in accordance with the Creative Commons Attribution Non Commercial (CC BY-NC 4.0) license, which permits others to distribute, remix, adapt, build upon this work noncommercially, and license their derivative works on different terms, provided the original work is properly cited and the use is non-commercial. See: http:// creativecommons.org/licenses/by-nc/4.0/

\section{REFERENCES}

1. Bagot $\mathrm{CN}$, Arya R. Virchow and his triad: a question of attribution. $\mathrm{Br}$ J Haematol 2008;143:180-90.

2. Dickson BC. Virchow's triad. Br J Haematol 2009;145:433.

3. Virchow R. "Thrombose und Embolie. Gefässentzündung und septische Infektion." Gesammelte Abhandlungen zur wissenschaftlichen Medicin (in German). Matzdorff AC, Bell WR (1998). Thrombosis and embolie (1846-1856). Canton, MA: Science History Publications. Frankfurt am Main: Von Meidinger \& Sohn, 1856.

4. Heit JA, Melton LJ III, Lohse CM, et al. Incidence of venous thromboembolism in hospitalized patients vs community residents. Mayo Clin Proc 2001;76:1102-10.

5. Merli GJ. Update. Deep vein thrombosis and pulmonary embolism prophylaxis in orthopedic surgery. Med Clin North Am 1993;77:397-411.

6. Spencer FA, Emery C, Lessard D, et al. The Worcester Venous Thromboembolism study: a population-based study of the clinical epidemiology of venous thromboembolism. J Gen Intern Med 2006;21:722-7.

7. Eikelboom JW, Weitz JI. Importance of family history as a risk factor for venous thromboembolism. Circulation 2011;124:996-7.

8. National Clinical Guideline Centre-Acute and Chronic Conditions (formerly the National Collaborating Centre for Acute Care) Venous thromboembolism: reducing the risk of venous thromboembolism (deep vein thrombosis and pulmonary embolism) in patients admitted to hospital 2010 [cited: 09/06/2014]. http://www.nice.org.uk/ nicemedia/live/12695/47920/47920.pdf

9. den Exter PL, vander Hulle $\mathrm{T}$, Lankeit $\mathrm{M}$, et al. Long-term clinical course of acute pulmonary embolism. Blood Rev 2013;27:185-92.

10. Alsawadi A, Loeffler M. Graduated compression stockings in hip fractures. Ann R Coll Surg Engl 2012;94:463-71.

11. Holmes J, House A. Psychiatric illness predicts poor outcome after surgery for hip fracture: a prospective cohort study. Psychol Med 2000;30:921-9.

12. National Institute for Health and Care Excellence. Venous thromboembolism—reducing the risk (CG92). 2010.[cited: 09/06/ 2014]. http://guidance.nice.org.uk/CG92

13. Royal College of Physicians. National clinical guideline for stroke 2012. [cited: 09/06/2014]. http://www.rcplondon.ac.uk/sites/default/ files/national-clinical-guidelines-for-stroke-fourth-edition.pdf

14. CLOTS (Clots in Legs Or sTockings after Stroke) Trial Collaboration. Thigh-length versus below-knee stockings for deep venous thrombosis prophylaxis after stroke: a randomized trial. Ann Intern Med 2010;153:553-62. 
15. [No authors listed]. Prevention of pulmonary embolism and deep vein thrombosis with low dose aspirin: Pulmonary Embolism Prevention (PEP) trial. Lancet 2000;355:1295-302.

16. Della Valle CJ, Steiger DJ, Di Cesare PE. Thromboembolism after hip and knee arthroplasty: diagnosis and treatment. J Am Acad Orthop Surg 1998;6:327-36.

17. Wilson D, Cooke EA, McNally MA, et al. Altered venous function and deep venous thrombosis following proximal femoral fracture. Injury 2002;33:33-9.

18. Fisher WD, Agnelli G, George DJ, et al. Extended venous thromboembolism prophylaxis in patients undergoing hip fracture surgery - the SAVE-HIP3 study. Bone Joint J 2013;95-B:459-66.

19. Warlow C, Ogston D, Douglas AS. Deep venous thrombosis of the legs after strokes. Part I-incidence and predisposing factors. Br Med J 1976;1:1178-81.

20. Sachdeva A, Dalton M, Amaragiri SV, et al. Elastic compression stockings for prevention of deep vein thrombosis. Cochrane Database Syst Rev 2010;(7):CD001484.

21. Barnes RW, Brand RA, Clarke W, et al. Efficacy of graded-compression antiembolism stockings in patients undergoing total hip arthroplasty. Clin Orthop Relat Res 1978;(132):61-7.

22. Bergqvist $D$, Lindblad $B$. The thromboprophylactic effect of graded elastic compression stockings in combination with dextran 70. Arch Surg 1984;119:1329-31.

23. Fredin H, Bergqvist D, Cederholm C, et al. Thromboprophylaxis in hip arthroplasty. Dextran with graded compression or preoperative dextran compared in 150 patients. Acta Orthop Scand 1989;60:678-81.

24. Hui AC, Heras-Palou C, Dunn I, et al. Graded compression stockings for prevention of deep-vein thrombosis after hip and knee replacement. J Bone Joint Surg Br 1996;78:550-4.

25. Ohlund C, Fransson SG, Starck SA. Calf compression for prevention of thromboembolism following hip surgery. Acta Orthop Scand 1983;54:896-9.

26. National Hip Fracture Database. National Report 2013-Summary. 2013. [cited]. http://www.nhfd.co.uk/20/hipfractureR.nsf/ luMenuDefinitions/F29405CD131D1F36802579C900553994/\$file/ NHFD\%20Summary\%20Report\%202013.pdf?OpenElement

27. Handoll HH, Farrar MJ, McBirnie J, et al. Heparin, low molecular weight heparin and physical methods for preventing deep vein thrombosis and pulmonary embolism following surgery for hip fractures. Cochrane Database Syst Rev 2002;(4): CD000305.

28. Morris RJ, Woodcock JP. Evidence-based compression: prevention of stasis and deep vein thrombosis. Ann Surg 2004;239:162-71.

29. [No authors listed]. RP Summary: recommended practices for prevention of deep vein thrombosis (DVT). AORN J 2011;94:455-6.

30. Warwick D, Dahl OE, Fisher WD. Orthopaedic thromboprophylaxis: limitations of current guidelines. J Bone Joint Surg Br 2008;90:127-32. 